\title{
DISTINCTIVE SORPTION MECHANISMS OF SOIL ORGANIC MATTER AND MINERAL COMPONENTS AS ELUCIDATED BY ORGANIC VAPOR UPTAKE KINETICS
}

\author{
YANG-HSIN SHIH* $†$ and SHIAN-CheE Wu \\ $\dagger$ Department of Soil and Environmental Sciences, Center of Nanoscience and Nanotechnology, National Chung Hsing University, \\ 250 Kuo-Kuang Road, Taichung 402, Taiwan, Republic of China \\ $\ddagger$ Graduate Institute of Environmental Engineering, National Taiwan University, 71 Chou-Shan Road, Taipei 106, Taiwan, Republic of China
}

(Received 14 March 2005; Accepted 20 May 2005)

\begin{abstract}
Sorption kinetics and capacities of volatile organic compounds (VOCs) affect the remediation and fate of these pollutants in soils. The soil organic-mineral compositional heterogeneity complicates the transport and fate of VOCs in soils. The sorption kinetics of toluene vapor with two common soil components, kaolinite and humic acid, shows two distinct sorption patterns. Results with kaolinite are characteristic of surface adsorption, whereas results with humic acid are characteristic of solvation and partition effects. On soils, the kinetics of toluene vapor sorption show a two-stage sorption phenomenon. The first stage is reflective of surface adsorption (1-4 h to completion) and the second stage of much slower partitioning into soil organic matter, which was preceded by a lag phase $(\sim 4 \mathrm{~h})$ and took as long as $15 \mathrm{~h}$ for completion. The relative contributions of these two stages to soil uptake are quantifiable by two independent parameters, the soil organic fraction and the surface area. A better understanding of the effect of soil compositional heterogeneity on sorption kinetics and capacities facilitates our understanding of the prediction for the fate of organic contaminants in the environment.
\end{abstract}

Keywords-Volatile organic compounds Humic acid Kaolinite Adsorption Partition

\section{INTRODUCTION}

The sorption of organic contaminants to soils is a major process affecting contaminant fate in natural systems. Volatile organic compounds (VOCs) are slowly sorbed into soil particles, and some of them could be retained in soil constituents over a long period of time [1-3]. Soil is a heterogeneous mixture of organic (e.g., humic acid, fulvic acid, and humin) and inorganic (e.g., quartz, clay, and salts) constituents. This heterogeneity affects the prediction of the activity and fate of a pollutant. Recent review articles have paid close attention to the slow sorption/desorption of organic compounds in natural solids $[1,4]$. This phenomenon has been attributed to the slow diffusion through soil micropore structures [5-7], through matrixes formed by condensed organic matter [8,9], and through the soil organic matter (SOM) [10-12]. Ball and Roberts [5] attributed the very low uptake rates of tetrachloroethene and 1,2,4,5-tetrachlorobenzene on aquifer material to the retarded transport of sorbate molecules in internal micropores. The results of Weber and Huang [8,9] indicate that sorption is slower in condensed organic matter. Brusseau et al. [11] found that intraorganic matter diffusion was responsible for the slow sorption in natural sorbents.

Numerous researchers have observed a biphasic process for the sorption of VOC by soils (i.e., an initial rapid rate followed by a later slow rate) [1,12-15]. Wu and Gschwend [16] explained the slow sorption in terms of a radial diffusion model in which the sorbate migrated into and out of the aggregated particles of organic matter and mineral components by diffusion. However, reports comparing the sorption kinetics of chemicals with individual soil components are sparse $[17,18]$. Here, we postulate that each soil component has its unique sorption mechanism and sorption kinetics. Delineation of the

\footnotetext{
* To whom correspondence may be addressed (yhs@ nchu.edu.tw).
}

sorption behaviors for each soil component would be of interest.

The hypothesis that sorption kinetics are affected by soil heterogeneity is tested by vapor sorption of the model VOC toluene (i.e., a low-molecular-weight, aromatic hydrocarbon) to model organic (i.e., humic acid) and inorganic (i.e., kaolinite) constituents as well as four natural soils that differ greatly in composition. Humic acid and kaolinite were selected as the two model soil components to represent SOM and soil inorganic matter (SIM). The sorption of toluene in humic acid and humin extracted from Yangmingshan (Taiwan) soil has been found to be reversible and diffusion controlled $[12,19]$. Sorption of VOCs at low concentrations to SIM proceeds, presumably, by surface adsorption. Kaolinite, a nonswelling clay mineral, is selected to be a model for SIM. The sorption kinetics and capacities were determined by microbalance on dried soils to examine the effect of soil heterogeneity on the soil sorption behaviors and dominant sorption mechanisms.

\section{MATERIALS AND METHODS}

Samples

Kaolinite (KGa-1) was obtained from the Source Clay Mineral Repository of the Clay Minerals Society (Department of Geography, University of Missouri, Columbia, MO, USA). Aldrich humic acid (sodium salt form) powder was purchased from Aldrich Chemical (Milwaukee, WI, USA). The organic carbon fraction of humic acid is 0.39 . The particle size of humic acid powder was measured with a Clias (Marcoussis, France) model 715 laser granulometer. The diameter of humic acid powder ranged from 100 to $800 \mu \mathrm{m}$, and the weighted average was approximately $270 \mu \mathrm{m}$. Four soil samples were collected from different locations in Taiwan: Taichung (TC), Chungli (CL), Kaikung (KK), and Yangmingshan (YM). Soil samples were air dried, freed of plant materials, and passed 
Table 1. The organic carbon contents $\left(f_{\text {oc }}\right)$ and surface areas $(\mathrm{SA})$ of the selected soil samples ${ }^{\mathrm{a}}$

\begin{tabular}{lllllllll}
\hline & TC & CL & KK & YM & TCD & CLD & KKD & YMD \\
\hline$f_{\text {oc }}$ & 0.010 & 0.016 & 0.031 & 0.12 & 0.0023 & 0.0034 & 0.0044 & 0.012 \\
SA $\left(\mathrm{m}^{2} / \mathrm{g}\right)$ & $8.5^{\mathrm{b}}$ & $23.3^{\mathrm{b}}$ & 6.42 & 3.80 & $7.70^{\mathrm{b}}$ & $25.95^{\mathrm{b}}$ & 7.65 & 47.05 \\
\hline
\end{tabular}

a Taichung (TC), Chungli (CL), Kaikung (KK), and Yangmingshan (YM) soils were collected from different locations in Taiwan. TCD, CLD, $\mathrm{KKD}$, and YMD soils are TC, CL, KK, and YM soils, respectively, after being treated by $\mathrm{H}_{2} \mathrm{O}_{2}$ to remove organic matter.

${ }^{\mathrm{b}}$ Chang [23].

through a 20-mesh $(0.84-\mathrm{mm})$ sieve. Then, the soil samples were stored in sealed bottles.

These four soil samples were treated with $30 \% \mathrm{H}_{2} \mathrm{O}_{2}$ at approximately $70^{\circ} \mathrm{C}$ to remove SOM following the procedure described by Kunze and Dixon [20]. The $\mathrm{H}_{2} \mathrm{O}_{2}$-treated soils are abbreviated as TCD from TC soil, CLD from CL soil, KKD from KK soil, and YMD from YM soil, respectively.

\section{Sample characterization}

Surface area and pore-size distribution measurements were carried out with an ASAP 2000 analyzer (Micrometrics Instrument, Norcross, GA, USA). Surface area was calculated from the nitrogen adsorption data using the Brunauer-EmmettTeller equation. The organic carbon fraction $\left(f_{\text {oc }}\right)$ was determined by use of a PerkinElmer Model $2400 \mathrm{CHN}$ analyzer (Norwalk, CT, USA) [21].

\section{Sorption experiment}

All samples were dried at $105^{\circ} \mathrm{C}$ for approximately $24 \mathrm{~h}$ to reach a constant weight before use. All measurements were made gravimetrically by use of a microbalance. Sorption experiments were replicated. The gravimetric apparatus has been described previously by Chang et al. [12] and by Shih and Wu $[19,22]$. In short, the sample in the holder was hung on the sample side of a Cahn D-200 electric microbalance (Madison, WI, USA) and was enclosed in a glass gas chamber. The sample was purged with $50 \mathrm{ml} / \mathrm{min}$ of $\mathrm{N}_{2}$ gas (hydrocarbon-free) to remove the sorbed impurity before each experiment. A steady flow of $\mathrm{N}_{2}$ gas was passed through the liquid toluene in a bottle and then mixed with a flow of pure $\mathrm{N}_{2}$ gas to produce a stream with a fixed concentration of the toluene vapor between 2.5 and $11.3 \mathrm{mg} / \mathrm{L}$. The experiment was terminated when the change in sample weight could not be distinguished from the base noise of the microbalance, which was approximately \pm 0.2 $\mu \mathrm{g}$. In the present study, the experimental apparatus was maintained at $25 \pm 0.1^{\circ} \mathrm{C}$ (mean \pm standard deviation). The concentration of the toluene was determined using a gas chromatography-flame ionization detector (model 5890II; HewlettPackard, Wilmington, DE, USA).

\section{RESULTS AND DISCUSSION}

\section{Characteristics of soils}

The properties of the eight soil samples are shown in Table 1. The organic contents of the four original soils increased in the following order: TC $<\mathrm{CL}<\mathrm{KK}<$ YM. After $\mathrm{H}_{2} \mathrm{O}_{2}$ treatment, the residual organic carbon content followed the same trend. The residual SOM content was, on average, $17 \%$ $\pm 6.0 \%$ of the original SOM content. The surface area remained largely comparable after removing most SOM in CL soil. This result was expected, because the clay fraction in CL was the dominant source of the surface area [23]. Interestingly, the surface areas of KKD soil and YMD soil were higher than those for the respective KK and YM soils. In YMD soil, 25\% of the surface was with micropores; however, no microporous surface was found in the original YM soil. The increased surface area may be with mesopores or micropores, which previously were covered by SOM. Kilduff et al. [24,25] found that pore blockage by natural organic matter makes a significant contribution in the reduction of surface area. Our results indicate that the accessible mineral surface area would be greatly overestimated in the organic content-removed soil samples, for which the original organic carbon content was in the range of $10 \%$, because much of the mineral surface will be covered by organic matter and much less area will be available for sorption. Conversely, in soils with organic contents of up to $3 \%$, such an effect does not seem to play a role.

\section{Sorption of toluene on two soil components}

The sorption kinetics of toluene vapor on kaolinite and humic acid are shown in Figure 1. The experimental conditions and the sorption results with kaolinite and humic acid are summarized in Table 2. It took approximately $4 \mathrm{~h}$ for the vapor uptake of toluene by kaolinite to reach a steady state. In comparison, the time for the toluene uptake by humic acid to reach a steady state was considerably longer $(\sim 15 \mathrm{~h})$.

\section{Sorption kinetics on clays}

The sorption kinetics of toluene on kaolinite showed only a single step and a relatively sharp transition zone (i.e., with $M_{t} / M_{e}$ increasing from 0 to 1 , where $M_{t}$ is the sorbed mass at time $t$ and $M_{e}$ is the ultimate sorbed mass) (Fig. 1), which is characteristic of the surface adsorption. Similar one-step sorption kinetics also have been documented by Morrissey and Grismer [17] for the uptake of several organic vapors on different clay minerals by a gravimetric method. Kaolinite, a

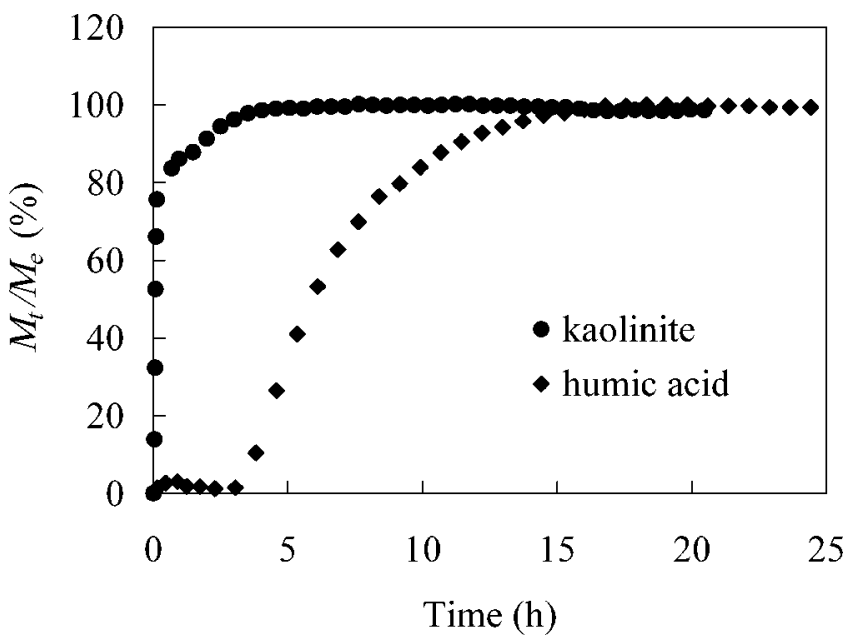

Fig. 1. Sorption kinetics of toluene on kaolinite and humic acid, presented as $M_{t} / M_{e}$ versus time, where $M_{t}$ is the sorbed mass at time $t$ and $M_{e}$ is the equilibrium sorbed mass. 
Table 2. Sorption of toluene vapor on two soil components

\begin{tabular}{lcc}
\hline & Kaolinite & Humic acid \\
\hline Surface area $\left(\mathrm{m}^{2} / \mathrm{g}\right)$ & 15.5 & 0.14 \\
Sample weight $(\mathrm{mg})$ & 183.4 & 70.0 \\
VOC pressure $\left(P / P_{\mathrm{o}}\right)^{\mathrm{a}}$ & 0.021 & 0.019 \\
& $(0.0013)$ & $(0.00079)$ \\
Concentration $(\mathrm{mg} / \mathrm{L})$ & 2.8 & 2.5 \\
Sorbed weight $(\mu \mathrm{g})$ & 255 & 205 \\
$K_{\mathrm{d}}(\mathrm{L} / \mathrm{g})$ & 0.502 & 1.17 \\
\hline
\end{tabular}

a The number shown is the average of three measurements; the number in parentheses is the standard deviation of the three measurements. VOC $=$ volatile organic compounds

common clay mineral in soils, provides a large surface area for the sorbate to adhere, in conformation to the presumed surface adsorption.

\section{Diffusion into humic substances}

The sorption of toluene to humic acid powder took approximately $15 \mathrm{~h}$ to reach equilibrium, and it showed a significant lag period in the beginning and a large transition zone before equilibrium (Fig. 1). Chang et al. [12] suggested that a lag period occurs because the vapor molecules must first solvate the outer layer of the humic acid before penetration of sorbate into the SOM matrix can occur. The prolonged uptake is caused by slow diffusion of toluene through the SOM matrix $[12,19,22]$. The average diffusivity of toluene into humic acid is $6.6 \times 10^{-9} \mathrm{~cm}^{2} / \mathrm{s}$ at $25^{\circ} \mathrm{C}$ [12]. The value for the diffusivity of toluene in humic substances is on the same order of magnitude [18,22]. Diffusivities for toluene in humic and fulvic acids are on the order of $3.84 \times 10^{-9} \mathrm{~cm}^{2} / \mathrm{s}$ and $8.51 \times 10^{-10}$ $\mathrm{cm}^{2} / \mathrm{s}$, respectively [18]. The time scale of diffusion through the thickness of natural SOM film on soil mineral surfaces or discrete particles can be estimated by the relationship $t=(\Delta x)^{2} /$ $2 D$, where $\Delta x$ is the thickness of the boundary layer surrounding the aggregate and $D$ is the diffusivity of sorbates $[12,26,27]$. By using the diffusivity of toluene in humic acid, $6.6 \times 10^{-9} \mathrm{~cm}^{2} / \mathrm{s}$ and the approximate diameter of humic acid powder $(270 \mu \mathrm{m})$, the time needed for diffusion into humic acid powder was calculated to be $15 \mathrm{~h}$. This time period is very close to that spanned by the transition zone of toluene vapor with the humic acid after an initial lag period (Fig. 1). This result is eminently consistent with the solvation/diffusion mechanism of VOCs with humic acids [12].

\section{Sorption process of soil samples}

A two-stage sorption process is observed for all soil samples (Figs. 2 and 3). For soils with low SOM contents (i.e., TC and CL soils), the first stage of the sorption process lasted approximately $1 \mathrm{~h}$, followed by a stagnant time of $1.7 \mathrm{~h}$ before it continued to the second stage. The second sorption stage spanned a much longer time compared to the first stage. A similar sorption pattern occurred for TCD and CLD soils. The capacities with the first-stage sorption for these soils are more than $70 \%$ of the total sorption capacities. The surface adsorption rate of VOCs on the SIM is much faster than that of the sorption of VOCs into humic substances under dry conditions (Fig. 1). Therefore, it is reasonable to suggest that the fast uptake process with the (dry) soil results mainly from the adsorption on mineral surfaces. It shows that under dry conditions, the adsorption of toluene on soil mineral matter is the dominant mechanism for these two soils that have low SOM

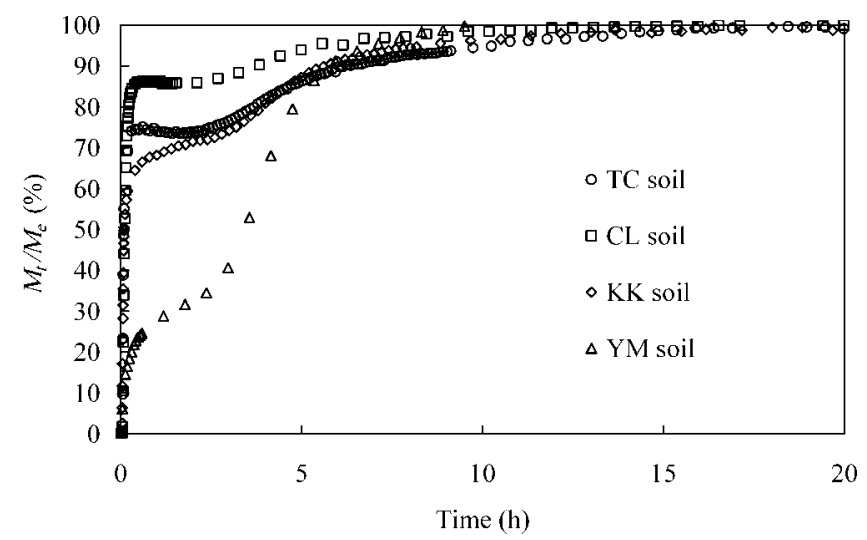

Fig. 2. Results of toluene sorption on four soils: Taichung (TC), Chungli (CL), Kaikuang (KK), and Yangmingshan (YM).

contents. This result coincides with the results of Yaron and Saltzman [28] and of Chiou and Shoup [29].

The YM soil showed the least sorption percentage for the first stage, which may be understood in terms of its high SOM and low mineral contents. After removing most of the SOM content, the percentage of sorption for the first stage with YMD soil increased significantly (Fig. 2). This enhancement is presumably a result of opening up the surface adsorption sites after removal of the SOM.

The experimental conditions and the corresponding sorption results are shown in Table 3. All experiments were performed under low toluene partial pressure. The relative saturation pressure $\left(P / P_{\mathrm{o}}\right)$ of toluene ranges from 0.019 to 0.086 , with the corresponding vapor concentrations ranging from 2.5 to $11.3 \mathrm{mg} / \mathrm{L}$. In this low concentration range, the distribution coefficient $K_{\mathrm{d}}$ (L gas/g solid) between the solid phase and the gaseous phase may be expressed as

$$
K_{\mathrm{d}}=\frac{q_{\mathrm{e}}}{C_{\mathrm{g}}}
$$

where $q_{\mathrm{e}}$ is the equilibrium sorbed amount $(\mathrm{mg} / \mathrm{g})$ and $C_{\mathrm{g}}$ is the corresponding toluene vapor concentration $(\mathrm{mg} / \mathrm{L})$.

The uptake by SOM also contributes to the soil sorption of organic compounds under dry conditions [30,31]. The relative abundance in SOM (represented by the organic carbon fraction) follows the order $\mathrm{YM}>\mathrm{KK}>\mathrm{CL}>\mathrm{TC}$. The distribution coefficients of these soils seem to follow the same trend; however, the $K_{\mathrm{d}}$ of CL (0.67) is slightly higher than that of KK (0.41). This may result from the larger surface area of

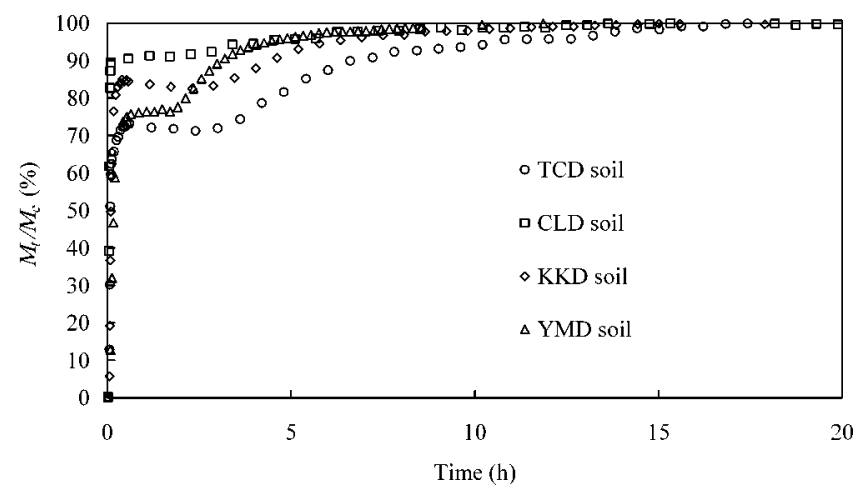

Fig. 3. Results of toluene sorption on four soils treated with $\mathrm{H}_{2} \mathrm{O}_{2}$ to remove organic matter: Taichung (TCD), Chungli (CLD), Kaikuang (KKD), and Yangmingshan (YMD). 


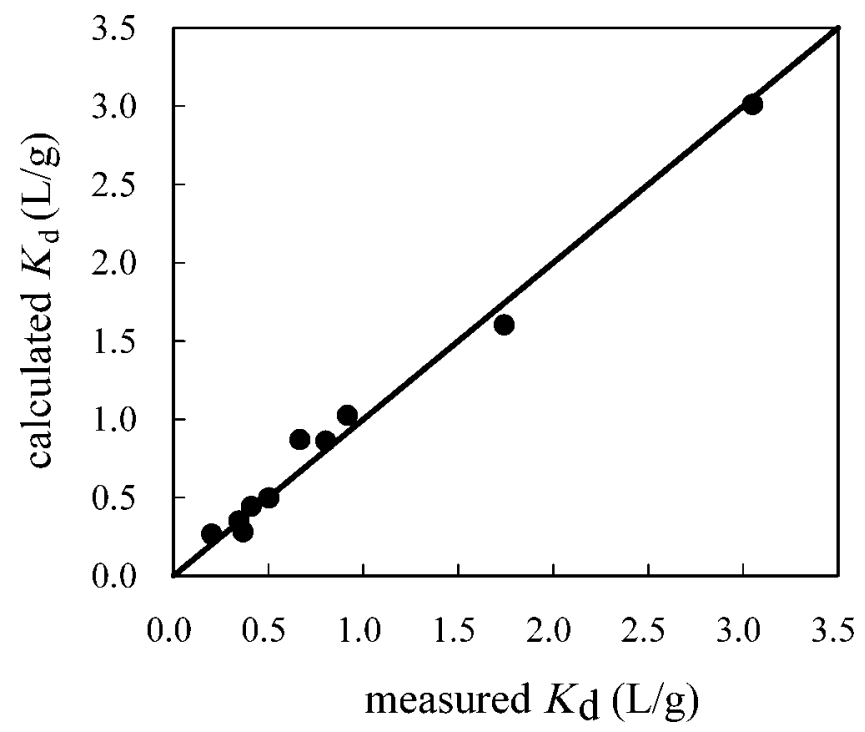

Fig. 4. Experimental distribution coefficients of toluene between solid and gaseous phases against estimated values through Equation 2.

CL soil compared to that of KK soil. The same pattern also was observed in the hydrogen peroxide-treated soils.

Sorption amount of organic contaminants in dry soils may be regulated both by the partition into SOM and by the surface adsorption on mineral surfaces. The amount of organic contaminants adsorbed on the surface of soils can be estimated by the surface area of soils and the surface-based distribution constant.

By using two independent parameters, the organic carbon fraction and the surface area, the distribution coefficient can be quantified via the following equation:

$$
K_{\mathrm{d}}=a f_{\mathrm{oc}}+b \mathrm{SA}
$$

where $f_{\mathrm{oc}}$ (dimensionless) is the organic carbon fraction in soil, $\mathrm{SA}\left(\mathrm{m}^{2} / \mathrm{g}\right)$ is the surface area of the soil, and both $a(\mathrm{~L} \mathrm{gas} / \mathrm{g}$ carbon) and $b\left(\mathrm{~L} / \mathrm{m}^{2}\right)$ are constants. These two constants were obtained by the multiple-variable regression of the distribution coefficients with respect to the $f_{\text {oc }}$ and SA values of the eight soils, kaolinite, and humic acid. The distribution coefficients of toluene in humic acid $(4.63$ and $3.63 \mathrm{~L} / \mathrm{g}$ ) have been measured [12]. The averaged distribution coefficient of these two measurements and $1.17(\mathrm{~L} / \mathrm{g})$ in Table 2, or $3.05(\mathrm{~L} / \mathrm{g})$, is used in the regression. The $a$ constant so obtained is $7.71 \pm 0.260$ ( $\mathrm{L}$ gas/g carbon), and the $b$ constant is $0.0321 \pm 0.00170(\mathrm{~L} /$ $\mathrm{m}^{2}$ ). The correlation fit was given by $R^{2}=0.99$ and $F=300$, respectively.

The comparison between the predicted toluene distribution coefficients by Equation 2 and the experimental values is presented in Figure 4. It shows that the distribution coefficients at low concentration ranges with different dry soils can be estimated with good accuracies by these two soil properties (surface area and organic carbon fraction).

In the sorption equilibrium aspect, the first term in Equation 2 , the contribution from SOM, is denoted as $K_{\mathrm{dc}}$. The second term, the contribution from the surface adsorption, is denoted as $K_{\mathrm{ds}}$. These two fractions are estimated from Equation 2 and are shown in Table 4 . The surface adsorption fraction, $K_{\mathrm{ds}}$, is generally larger than the SOM sorption fraction, $K_{\mathrm{dc}}$, except for KK and YM soils (because of their higher SOM content). As seen in Table 4 , the estimated values of $K_{\mathrm{ds}} / K_{\mathrm{d}}$ and $K_{\mathrm{dc}} / K_{\mathrm{d}}$ approximately correspond to the percentage $M_{t} / M_{e}$ of initial 
Table 4. Experimental and predictive two-stage sorption results of toluene ${ }^{a}$

\begin{tabular}{lcccccccc}
\hline & TC & CL & KK & YM & TCD & CLD & KKD & YMD \\
\hline First-stage sorbed fraction $(\%)^{\mathrm{b}}$ & 74.0 & 86.0 & 71.5 & 30.0 & 71.9 & 89.4 & 83.6 & 76.5 \\
${\text { Second-stage sorbed fraction }(\%)^{\mathrm{c}}}$ & 26.0 & 14.0 & 28.5 & 70.0 & 28.0 & 10.6 & 16.4 & 23.5 \\
$K_{\mathrm{ds}}(\mathrm{L} / \mathrm{g})^{\mathrm{d}}$ & 0.27 & 0.75 & 0.21 & 0.12 & 0.25 & 0.83 & 0.25 & 1.51 \\
$K_{\mathrm{dc}}(\mathrm{L} / \mathrm{g})^{\mathrm{e}}$ & 0.08 & 0.12 & 0.24 & 0.90 & 0.02 & 0.03 & 0.03 & 0.09 \\
$K_{\mathrm{dd}} / K_{\mathrm{d}}(\%)$ & 78.0 & 85.9 & 46.6 & 11.9 & 93.3 & 96.9 & 87.9 & 94.2 \\
$K_{\mathrm{dc}} / K_{\mathrm{d}}(\%)$ & 22.0 & 14.1 & 53.4 & 88.1 & 6.7 & 3.1 & 12.1 & 5.8 \\
\hline
\end{tabular}

a See Table 1 for column-head abbreviations.

${ }^{\mathrm{b}}$ The first sorbed fraction can be estimated by the level of the first plateau between two stages in Figures 2 and 3.

c The difference in sorption fraction between the first plateau and the ultimate plateau in Figures 2 and 3.

${ }^{\mathrm{d}}$ The predicted distribution coefficient of toluene with the soil surface by Equation 2.

${ }^{\mathrm{e}}$ The predicted distribution coefficient of toluene with the soil organic carbon by Equation 2.

fast adsorption and the remaining percentage $M_{t} / M_{e}$ of slow secondary absorption, respectively.

A predictive equation for absorption. The sorption constant of a nonpolar organic chemical to soil organic carbon generally is predicted via a correlation from the known octanol partition constant of the respective compound ignoring adsorption on mineral surfaces $[32,33]$ :

$$
K_{\mathrm{dc}}=f_{\mathrm{oc}} \cdot K_{\mathrm{soc} / \mathrm{air}}=f_{\mathrm{oc}} \cdot 0.000411 K_{\mathrm{octanol} / / \mathrm{air}}
$$

where $K_{\text {soc/air }}$ is the air/soil organic carbon sorption constant and $K_{\text {octanol/air }}$ is the partition constant between octanol and water. The equation was derived from an aqueous-phase sorption experiment, so this correlation strictly holds only for completely hydrated SOM [34]. Compared to Equation 2, the $a$ constant is equivalent to $K_{\text {soc/air }}$ in Equation 3. The estimation of $K_{\text {soc/air }}$ for toluene from Equation $3(0.73)$ is less than the $a$ constant of 7.71. The higher $a$ constant could result from the dry experimental condition. Borisover and Graber [35] indicated that hydration of the natural organic matter phase can differentiate between sorption of organic compounds by two to three orders of magnitude.

A predictive equation for adsorption. Regarding adsorption on mineral surfaces, Goss et al. [32-34,36] recently used linear free-energy relationships to describe the surface area-normalized adsorption constant, $K_{\mathrm{SA}}\left(\mathrm{m}^{3} / \mathrm{m}^{2}\right.$ at $\left.15^{\circ} \mathrm{C}\right)$, as a function of the van der Waals, e-donor, and e-acceptor properties of the adsorbate as well as the surface at different humidities as follows:

$$
\begin{aligned}
\log K_{\mathrm{SA}}= & 0.136 \log K_{\text {hexadecane/air }} \sqrt{\gamma_{\mathrm{s}}^{v d W}}+5.13\left(\sum \beta_{2}^{H}\right) \mathrm{EA}_{\mathrm{s}} \\
& +3.60\left(\sum \alpha_{2}^{H}\right) \mathrm{ED}_{\mathrm{s}}-8.47
\end{aligned}
$$

where $K_{\text {hexadecane/air }}$ is the partition constant between hexadecane and air and $\Sigma \beta_{2}^{H}$ and $\Sigma \alpha_{2}^{H}$ are the e-donor and e-acceptor properties, respectively, of the studied adsorbate. These descriptors are tabulated for a large number of compounds [37,38]. The terms $V \gamma_{\mathrm{s}}^{v d W}, \mathrm{EA}_{\mathrm{s}}$, and $\mathrm{ED}_{\mathrm{s}}$ are used to describe the van der Waals, e-acceptor, and e-donor properties of the surface, respectively. These surface descriptors of different sorbents under different humidities were determined by Goss et al. [32,34].

Based on the surface descriptors of clay minerals at $15^{\circ} \mathrm{C}$ measured by Goss et al. [32] and the sorbate descriptors of toluene, the values of $K_{\mathrm{SA}}$ at 50,70, and $90 \%$ relative humidity were predicted. These predicted surface area-normalized adsorption constants were extrapolated to $25^{\circ} \mathrm{C}$ with the van't Hoff equation, whereas the enthalpy of adsorption can be estimated by the following relationship: $\Delta H=-10.2 \cdot \log K_{\mathrm{SA}}$ - 89.6, where $\Delta H$ is the enthalpy of adsorption $[33,39]$. The calculated values of $K_{\mathrm{SA}}$ and the $b$ constant in thepresent study, equivalent to $K_{\mathrm{SA}}$, are plotted in Figure 5. A good log-linear relationship suggests that the values of $K_{\mathrm{SA}}$ exponentially decrease with increasing relative humidity. This inverse exponential relationship between $K_{\mathrm{SA}}$ and relative humidity has been observed by Goss and Schwarzenbach [36], so the $b$ constant coincides with the trend of the literature data.

\section{Implication of the findings}

The soil samples were not water saturated in the present study, as they normally are in the natural subsurface. The capacity of surface adsorption is correspondingly smaller under conditions of high humidity than it is under low humidity [40-42]. After combining our data under $0 \%$ relative humidity with the results of Goss et al. [32], the good linearity of the relationship between $\ln K_{\mathrm{SA}}$ and relative humidity may allow extrapolation to different humidities.

The estimation of sorption capacity of VOCs and kinetic behavior of heterogeneous soils is difficult in unsaturated soil conditions. The overall sorption kinetics and equilibrium can be described as being composed of adsorption and absorption, where adsorption takes place mainly on mineral surfaces and absorption in organic matter. The soil sorption capacity can

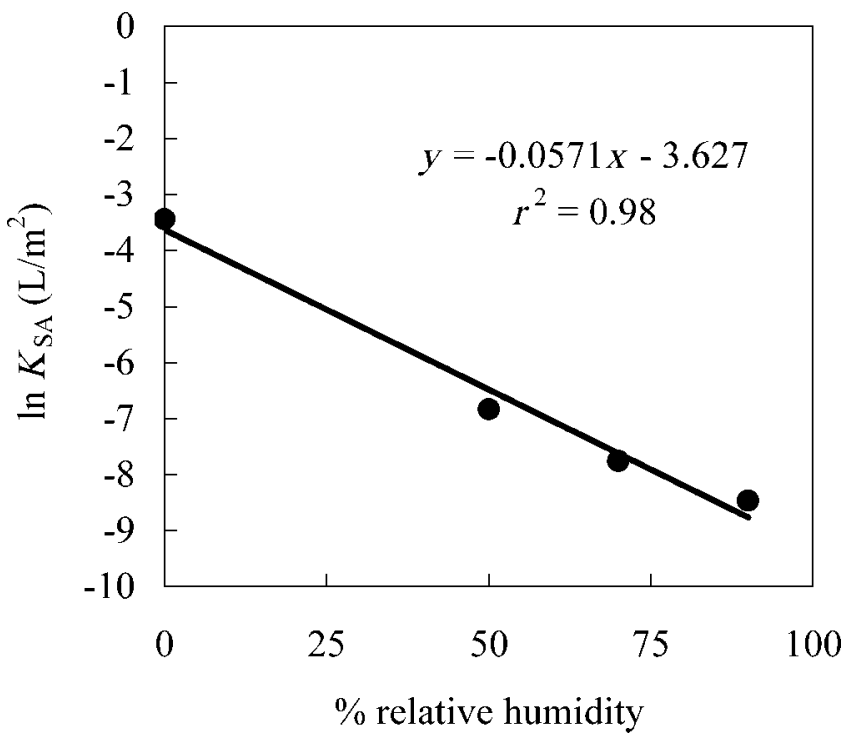

Fig. 5. Relative humidity dependence of the surface-normalized adsorption coefficient for toluene at $25^{\circ} \mathrm{C}$. The values of $K_{\mathrm{SA}}$ at 50,70 , and $90 \%$ relative humidity were calculated with Equation 4, whereas the surface descriptors of clay minerals and the sorbate descriptors of toluene were taken from the literature $[32,37,38]$. 
be estimated by summing the capacities from individual soil components, which allows one to estimate the sorption amount as well as the dominant sorption mechanism of a composite soil sample. By using only two independent soil properties, the organic carbon fraction $\left(f_{\text {oc }}\right)$ and the surface area (SA), the distribution coefficient of VOCs between soil and air phases can be estimated.

Acknowledgement-We gratefully acknowledge the financial support of the National Science Council of Taiwan, Republic of China (contracts NSC 91-2211-E-002-062 and NSC 93-2313-B-005-088). Constructive comments from the editor (Gerrit Schüürmann), Cary T. Chiou, and anonymous reviewers helped improve an earlier version of this paper.

\section{REFERENCES}

1. Pignatello JJ, Xing B. 1996. Mechanisms of slow sorption of organic chemicals to nature particles. Environ Sci Technol 30:111 .

2. Aochi YO, Farmer WJ. 1995. Spectroscopic evidence for the ratelimited accumulation of a persistent fraction of 1,2-dichloroethane sorbed onto clay minerals. Environ Sci Technol 29:1760-1765.

3. Steinberg SM, Pignatello JJ, Sawney BL. 1987. Persistence of 1,2-dibromoethane in soils: Entrapment in intraparticle micropores. Environ Sci Technol 21:1201-1208.

4. Luthy RG, Aiken GR, Brusseau ML, Cunningham SD, Gschwend PM, Pignatello JJ, Reinhard M, Traina SJ, Weber WJ Jr, Westall JC. 1997. Sequestration of hydrophobic organic contaminants by geosorbents. Environ Sci Technol 31:3341-3347.

5. Ball WP, Roberts PV. 1991. Long-term sorption of halogenated organic chemicals by aquifer material. 2. Intraparticle diffusion. Environ Sci Technol 25:1237-1249.

6. Lin T, Little JC, Nazaroff WW. 1994. Transport and sorption of volatile organic compounds and water vapor within dry soil grains. Environ Sci Technol 28:322-330.

7. Farrell J, Reinhard M. 1994. Desorption of halogenated organics from model solids, sediments, and soil under unsaturated conditions. 1. Isotherms. Environ Sci Technol 28:63-72.

8. Weber WJ, Huang W. 1996. A distributed reactivity model for sorption by soils and sediments. 4 . Intraparticle heterogeneity and phase-distribution relationships under nonequilibrium conditions. Environ Sci Technol 30:881-888.

9. Huang W, Weber WJ Jr. 1998. A distributed reactivity model for sorption by soils and sediments. 11. Slow concentration-dependent sorption rates. Environ Sci Technol 32:3549-3555.

10. Fu G, Kan AT, Tomson M. 1994. Adsorption and desorption hysteresis of PAHs in surface sediment. Environ Toxicol Chem 13:1559-1567.

11. Brusseau ML, Jessup RE, Rao PSC. 1991. Nonequilibrium sorption of organic chemicals: Elucidation of processes. Environ Sci Technol 25:134-142.

12. Chang M, Wu S, Chen C. 1997. Diffusion of volatile organic compounds in pressed humic acid disks. Environ Sci Technol 31: 2307-2312.

13. Paviostathis SG, Mathavan GN. 1992. Desorption kinetics of selected volatile organic compounds from field-contaminated soils. Environ Sci Technol 26:532-538.

14. Pavlostathis SG, Jaglal K. 1991. Desorption behavior of trichloroethylene in contaminated soil. Environ Sci Technol 25:274279.

15. Pignatello JJ. 1990. Slowly reversible sorption of aliphatic halocarbons in soils. II. Mechanistic aspects. Environ Toxicol Chem 9:1117-1126.

16. Wu S, Gschwend PM. 1986. Sorption kinetics of hydrophobic organic compounds to natural sediments and soils. Environ Sci Technol 20:717-725.

17. Morrissey FA, Grismer ME. 1999. Kinetics of volatile organic compound sorption/desorption on clay minerals. J Contam Hydrol 36:291-312.

18. Piatt JJ, Brusseau ML. 1998. Rate-limited sorption of hydrophobic organic compounds by soils with well-characterized organic matter. Environ Sci Technol 32:1604-1608.

19. Shih Y, Wu S. 2002. Kinetics of toluene sorption in humin under two different levels of relative humidity. J Environ Qual 31:970978.

20. Kunze GW, Dixon JB. 1986. In Kulte A, ed, Methods of Soil Analysis, Part 1-Physical and Mineralogical Properties, 2nd ed. American Society of Agronomy, Madison, WI.

21. Nelson DW, Sommers LE. 1982. Total carbon, organic carbon, and organic matter. In Page AL, ed, Methods of Soil Analysis, Part 2-Chemical and Microbiological Properties, 2nd ed. American Society of Agronomy, Madison, WI.

22. Shih Y, Wu S. 2002. Sorption kinetics of selected volatile organic compounds in humin. Environ Toxicol Chem 21:2067-2074.

23. Chang M. 1998. Sorption and desorption kinetics of volatile organic vapor in soil. PhD thesis. National Taiwan University, Taipei, Taiwan.

24. Kilduff JE, Karanfil T, Weber WJ Jr. 1998. Competitive effects of nondisplaceable organic compounds on trichloroethylene uptake by activated carbon. I. Thermodynamic predictions and model sensitivity analyses. J Colloid Interface Sci 205:271-279.

25. Kilduff JE, Wigton A. 1999. Sorption of TCE by humic-preloaded activated carbon: Incorporating size exclusion and pore blockage phenomena in a competitive adsorption model. Environ Sci Technol 33:250-256.

26. Shih Y, Wu S. 2004. Kinetics of toluene sorption and desorption in $\mathrm{Ca}$ - and $\mathrm{Cu}$-montmorillonites investigated with Fourier transform infrared spectroscopy under two different levels of humidity. Environ Toxicol Chem 23:2061-2067.

27. Schwarzenbach RP, Gschwend PM, Imboden DM. 2002. Environmental Organic Chemistry. John Wiley, New York, NY, USA.

28. Yaron B, Saltzman S. 1972. Influence of water and temperature on adsorption of parathion by soils. Soil Sci Soc Am J 36:583586.

29. Chiou CT, Shoup TD. 1985. Soil sorption of organic vapors and effects of humidity on sorptive mechanism and capacity. Environ Sci Technol 19:1196-1200.

30. Rutherford DW, Chiou CT. 1992. Effect of water saturation in soil organic matter on the partition of organic compounds. Environ Sci Technol 21:965-970.

31. Chiou CT, Kile DE. 1994. Effects of polar and nonpolar groups on the solubility of organic compounds in soil organic matter. Environ Sci Technol 28:1139-1144.

32. Goss KU, Buschmann J, Schwarzenbach RP. 2004. Adsorption of organic vapors to air-dry soils: Model predictions and experimental validation. Environ Sci Technol 38:3667-3673.

33. Goss KU. 2004. The air/surface adsorption equilibrium of organic compounds under ambient conditions. Crit Rev Environ Sci Technol 34:339-389.

34. Goss KU, Buschmann J, Schwarzenbach RP. 2003. Determination of the surface sorption properties of talc, different salts and clay minerals at various relative humidities using adsorption data of a diverse set of organic vapors. Environ Toxicol Chem 22:26672672.

35. Borisover M, Graber ER. 2004. Hydration of natural organic matter: Effect on sorption of organic compounds by humin and humic acid fractions versus original peat material. Environ Sci Technol 38:4120-4129.

36. Goss KU, Schwarzenbach RP. 2002. Adsorption of a diverse set of organic vapors on quartz, $\mathrm{CaCO}_{3}$ and $\alpha-\mathrm{Al}_{2} \mathrm{O}_{3}$ at different relative humidities. $J$ Colloid Interface Sci 252:31-41.

37. Abraham MH, Chadha HS, Whiting GS, Mitchell RC. 1994. Hydrogen bonding. 32. An analysis of water-octanol and water-alkane partitioning and the $\Delta \log P$ parameter of Seiler. J Pharm Sci 83:1085-1100.

38. Abraham MH, Andonian-Haftvan J, Whiting GS, Leo A, Taft RS. 1994. Hydrogen bonding. Part 34: The factors that influence the solubility of gases and vapors in water at $298 \mathrm{~K}$, and a new method for its determination. J Chem Soc Perkin Trans 2:1777-1791.

39. Goss KU, Schwarzenbach RP. 1999. Empirical prediction of heats of vaporization and heats of adsorption of organic compounds. Environ Sci Technol 33:3390-3393.

40. Chiou CT. 2002. Partition and Adsorption of Organic Contaminants in Environmental Systems. John Wiley, New York, NY, USA.

41. Goss KU. 1992. Effects of temperature and relative humidity on the sorption of organic vapors on quartz sand. Environ Sci Technol 26:2287-2294.

42. Goss KU. 1993. Effects of temperature and relative humidity on the sorption of organic vapors on clay minerals. Environ Sci Technol 27:2127-2132. 